\title{
Nucleic Acid-programmed Assemblies: Translating Instruction into Function in Chemical Biology
}

\author{
Nicolas Winssinger
}

\begin{abstract}
The predictability of nucleic acid hybridization offers an attractive platform to program the assembly of tagged ligands or reactants. Hybridization can be used to display multiple ligands in order to gain affinity and/ or selectivity through the cooperative interaction of each ligand. Additionally, hybridization of tagged reagents increases their effective concentration and accelerates reactions. In both cases, an oligonucleotide directs an assembly to yield a functional output in the form of enhanced binding, inhibition, or reaction; for example, a reaction can be used to unmask a fluorophore or a bioactive molecule. This review provides an account of our research in this area as well as future directions.
\end{abstract}

Keywords: DNA · Multivalency $\cdot$ PNA · Self-assembly $\cdot$ Templated reactions

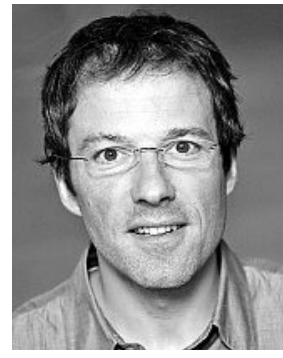

Nicolas Winssinger, a native of Belgium, received a BSc from Tufts University and a $\mathrm{PhD}$ with K.C. Nicolaou at the Scripps Research Institute. He then trained as an NIH postdoctoral fellow with Peter Schultz, also at the Scripps Research Institute. In 2002, he became an assistant professor at the University of Strasbourg (formerly University Louis Pasteur) at the Institut de Science et d'Ingénierie Supramoléculaires and was promoted to full professor in 2005. Shortly thereafter, he was elected to the Institut Universitaire de France (IUF). He joined the Organic Chemistry department at the University of Geneva in 2012. His research interests lie in bioorganic chemistry focusing on the development of chemical methods to understand complex biological systems. An integral part of these endeavors is the use of bioactive small molecules that can modulate protein function, particularly biologically validated natural products. These efforts are aided by the use of peptide nucleic acids (PNA) to encode molecules. A significant theme extending from this research is the use of oligonucleotides to program either spatial organization of ligands or chemical reactions.

\footnotetext{
${ }^{*}$ Correspondence: Prof. N. Winssinger

Department of Organic Chemistry

University of Geneva

30 quai Ernest Ansermet

$\mathrm{CH}-1211$ Geneva

Tel.: +41223796105

E-mail: nicolas.winssinger@unige.ch
}

\section{Introduction}

Nucleic acids are increasingly used to tag chemical entities (small molecules, peptides, proteins or glycans) in order to 'barcode' these entities or program their assemblies. As a barcode, nucleic acid tagging offers a remarkably efficient encoding system. A 25 mer oligomer can be used to generate over $10^{15}$ unique sequences. While a significant portion of these sequences would not be usable as a barcode to avoid self-hybridization, cross-hybridization and unbalanced GC distribution resulting in heterogeneous melting temperature $\left(T_{\mathrm{m}}\right)$, sets of $>10^{5}$ have been experimentally validated. ${ }^{[1,2]}$ In a pioneering application of DNA barcoding, a library of yeast deletion mutants was tagged with unique 20 mer sequences that were decoded by hybridization to a high-density oligonucleotide microarray. ${ }^{[3]}$ This technology was subsequently used to systematically determine the function of Saccharomyces cerevisiae's 6925 open reading frames (ORFs). ${ }^{4]}$ The prospect of using DNA to encode libraries of small molecules was first proposed by Lerner and Brenner ${ }^{[5]}$ and provided an elegant solution to track combinatorial synthesis by the powerful scheme of split and mix combinatorial synthesis. ${ }^{6]}$ Advent in microarray technologies ${ }^{[7]}$ and next-generation DNA sequencing ${ }^{[8]}$ will undoubtedly continue to facilitate our capacity to analyze complex mixtures of oligonucleotide tags at reduced costs, making technologies leverage on nucleic acid barcoding increasingly attractive. As a structuring element, pioneering work of Seeman and coworkers ${ }^{[9]}$ laid the foundation for rationally designed nanoscale objects. This concept is increasingly used for the design of 2D and 3D objects from the bottom up..$^{[10-13]}$ The specific bonding between nucleobases is a powerful tool to direct assembly in a programmable fashion. While the interactions between single nucleobases are rather weak and highly dynamic, the cooperativity achieved in oligomers leads to high stability. In practice, a 20mer oligonucleotide affords a duplex that is stable at room temperature at low $\mathrm{nM}$ concentration. Although high stability has been observed in many supramolecular systems, the remarkable feature of nucleic acid-based assemblies is that stable duplex can still exchange through strand invasion/displacement mechanism. This exchange facilitates correction of erroneous hybridization of mismatches when challenged with the perfect match sequence and provides a high fidelity in the self-sorting process when complex mixtures are present. While the complexity of nucleic acid-based assemblies used in chemical biology has remained modest compared to the achievement reported in nanosciences, advents in the latter are bound to inspire new applications in chemical biology. After all, Mother Nature most likely still holds the record for the most extraordinary nucleic acidbased assembly with the ribosome. Our ability to design architectures with appending functionalities extending beyond the four nucleobases will certainly open new horizons in the function and applications of nucleic acid-based assemblies.

Our work using nucleic acid tagging makes use of an unnatural oligomer: peptide nucleic acid[14,15] (PNA, Fig. 1). This choice was motivated by three distinctive features of PNA: i) PNA are more robust 
than DNA (chemically and biologically); ii) PNA:DNA duplex are more stable than DNA:DNA duplex and less sensitive to the ionic strength of the medium; iii) The synthesis of oligomers employs simple peptide couplings with a broad combination of possible protecting group chemistries and does not require harsh oxidative conditions. Modifications at the $\mathrm{C}(2)$ or $\mathrm{C}(5)$ positions (Fig. 1) of PNA are known to be tolerated and can be used to derivatize PNA with functional molecules in addition to the $\mathrm{C}$ - and $\mathrm{N}$-terminal or nucleobase positions. ${ }^{[16]}$ An important example of these modifications is the incorporation of D-arginine instead of glycine providing a guanidinium group at the $\mathrm{C}(2)$ ( $\alpha$ position) of a PNA monomer (so called GPNA) .[17] Oligomers containing four or more GPNA residues have been shown to be cell permeable and have moderately enhanced affinity. Another important modification is at the $C(5)$ ( $\gamma$ position) with the side chain of diverse L-amino acids. [18-20] The chirality at this position confers a helicity to the PNA, which further enhances its affinity and specificity for DNA. Modifications at either position can also be used to enhance solubility of PNAs, which may otherwise be a limiting factor in some applications.

\section{Combinatorial Synthesis of Encoded Libraries}

An important application of nucleic acid tagging is to encode small molecules. ${ }^{[21-23]}$ The discovery of small molecules that perturb a given biological pathway by binding to a specific target lies at the core of chemical biology and drug discovery. While highthroughput screening (HTS) approaches have proven effective, there remains a need to accelerate the discovery of bioactive compounds and reduce the overall costs, particularly as chemical biology probes. ${ }^{[24]}$ Nucleic acid-tagged libraries are attractive because binders can be identified by affinity selection without a priori knowledge of the target, as opposed to competition assays frequently used in HTS. Additionally, nucleic acid-tagged libraries use a highly miniaturized format that is operationally simple compared to microtiter plate-based format and require only a few micrograms of protein without complex robotics. Both DNA and PNA platforms have been used successfully to encode small molecule libraries with the first libraries reported in 2004. ${ }^{[25-30]}$ PNA encoded synthesis (PES) is facilitated by the fact that it can be carried out using conventional solid phase synthesis. ${ }^{[31]}$ Starting with a resin loaded with a bifunctional linker (such as lysine) bearing orthogonal protecting groups, the synthesis of the small molecule can be carried out alongside the PNA synthesis (Fig.

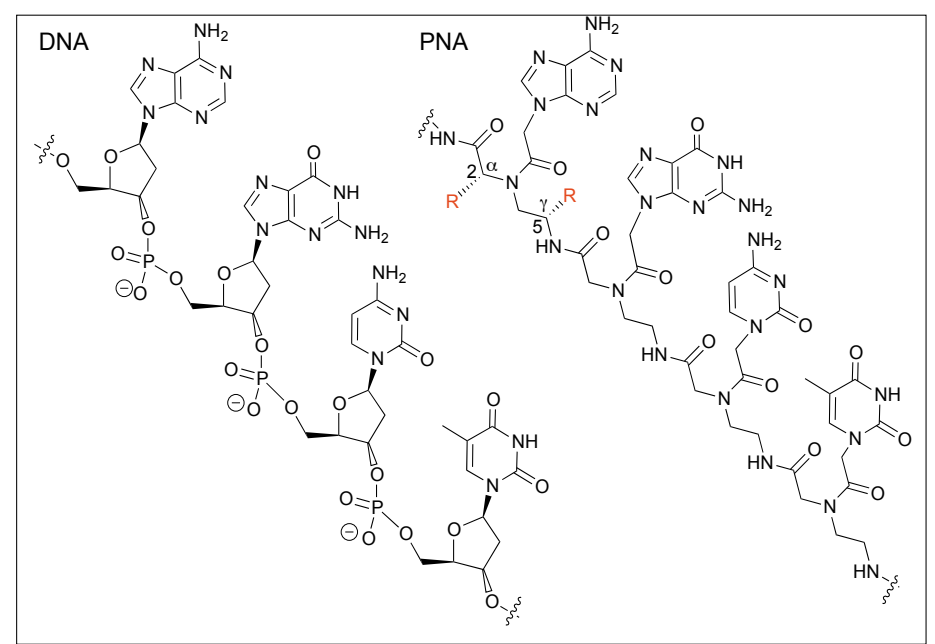

Fig. 1. DNA and PNA structures. Chemical structures of DNA (left) and PNA (right). Modifications at the $\alpha$ or $\gamma$ position of PNA $(R)$ are tolerated and may even enhance DNA or RNA hybridization.

2A). At every step of the synthesis where a synthon of diversity is introduced, the resin is split into the different pools for the individual reactions and its PNA encoding. Based on the high duplex stability of PNA, a 14 mer tag is sufficiently long to provide stable immobilization onto a DNA template in solution or on a microarray at $37^{\circ} \mathrm{C}$. Ultimately, an important criterion for nucleic acid-encoded libraries will be the quality and the scope of the chemistry performed in order to access a relevant diversity space. Fig. 2B illustrates libraries that have been reported by our group covering different classes of compounds: heterocycles traditionally recognized as good pharmacophores, ${ }^{[32]}$ mechanismbased peptidic libraries, ${ }^{[26,27,33,34]}$ a library of fluorogenic peptide substrate ${ }^{[25]}$ and a library of glycans. ${ }^{[35]}$ To date, several strategies have been reported for othogonal PNA with small molecules co-synthesis. ${ }^{[27,36-39]}$ A particularly robust scheme uses Mttprotected PNA monomers that are orthogonal to Fmoc-based synthesis and compatible with a large palette of reactions that have been productively used in diversity-oriented synthesis (DOS): palladium cross-couplings, metathesis, reductive amination, amidation, heterocycle formation, nucleophilic addition, conjugate additions, Pictet-Spengler cyclization. [39]

\section{Ligand Display}

The nucleic acid tag serves as a 'barcode' for the small molecule, facilitates the synthesis of libraries using the mix and split strategy but can also be used to program different assemblies. An attractive opportunity uses the tag to program the combinatorial assembly of different pharmacophores (Fig. 3) in order to tap into potential cooperative interactions with a target. An appealing feature of this display is that the DNA template can also be used to modulate the distance between ligands. Double-strand nucleic acid is fairly rigid with well-defined nucleobase spacing, allowing their use as a crude molecular ruler over short distances. Our group and others have used this strategy with a typical gain in binding affinity ranging from 10- to 1000-fold as a result of the synergic interaction of displayed ligands. $[32,35,40-50]$ Pioneering efforts in the area were reported by Kobayashi and coworkers with the oligomerization of a half slide complementary DNA fragment derivatized with galactose to generate periodic glycocluster. ${ }^{[51,52]}$ Neri and coworkers were the first to use complementary sequences within the tag to pair small molecule fragments using self-hybridization. The strategy was used first to pair a small library of drug fragments with a known pharmacophore to increase affinity. ${ }^{[30]}$ Displaying ligands on a DNA template rather than through selfcomplementation offers the advantage that the pairing and distances are controlled through the instructions in the template. Thus, the same nucleic acid-tagged molecules can be arranged in a variety of controlled pairing and distance using a library of templates. Furthermore, these templates can be in solution or on a microarray. Our first efforts aimed to demonstrate that this templated self-assembly could be used to recapitulate the geometry of ligands participating in multivalent interactions. ${ }^{[40]}$ We aimed to emulate the epitope of HIV, which is made up of multiple copies of a high mannose undecasaccharide (Fig. 4). An antibody that broadly neutralizes HIV, 2G12, was found to derive its affinity by forming an interlocked dimer that recognizes multiple units of the terminal mannose disaccharide with a well-defined spatial geometry. ${ }^{[53]}$ A small library of glycans including mannose disaccharides was assembled into 30 different combinations of glycan pairing and inter-glycan distances and their affinity for $2 \mathrm{G} 12$ was measured by SPR. Interestingly, a very clear distance-affinity relationship was observed with the anticipated selectivity for the mannose disaccharide. The calcu- 


\section{A. PNA-encoded synthesis (PES) using split and mix technique}
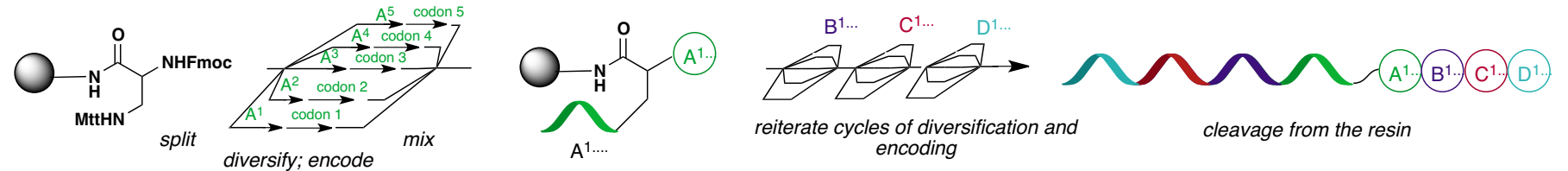

encoding

cleavage from the resin

B. Selected examples of heterocyclic libraries, peptidic libraries, and glycan library

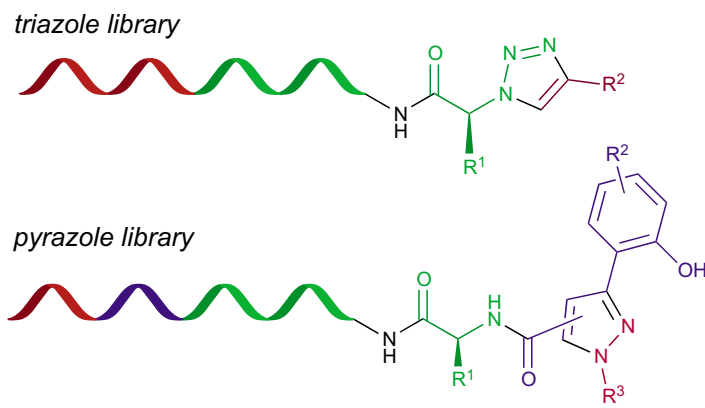

library targeting cysteine proteases with mechanism-based covalent trap

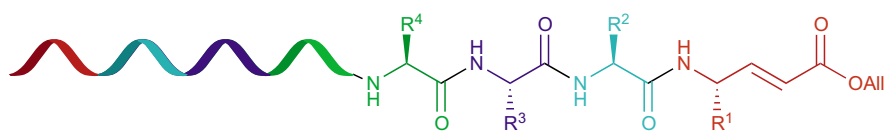

library targeting serine proteases with mechanism-based covalent trap
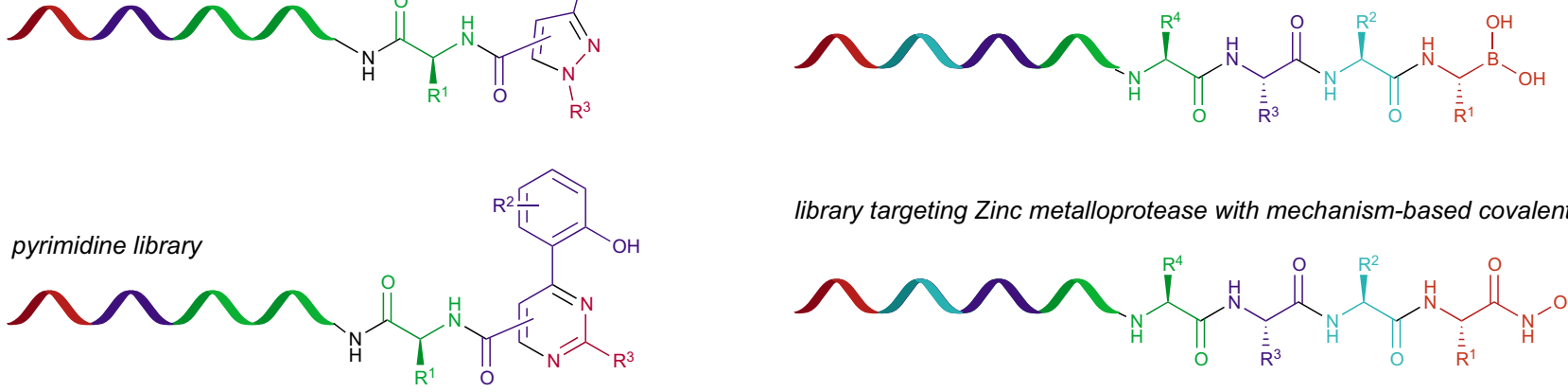

library targeting Zinc metalloprotease with mechanism-based covalent trap

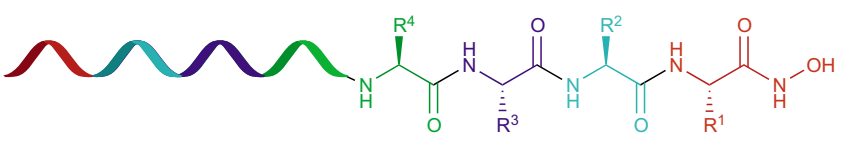

glycan library
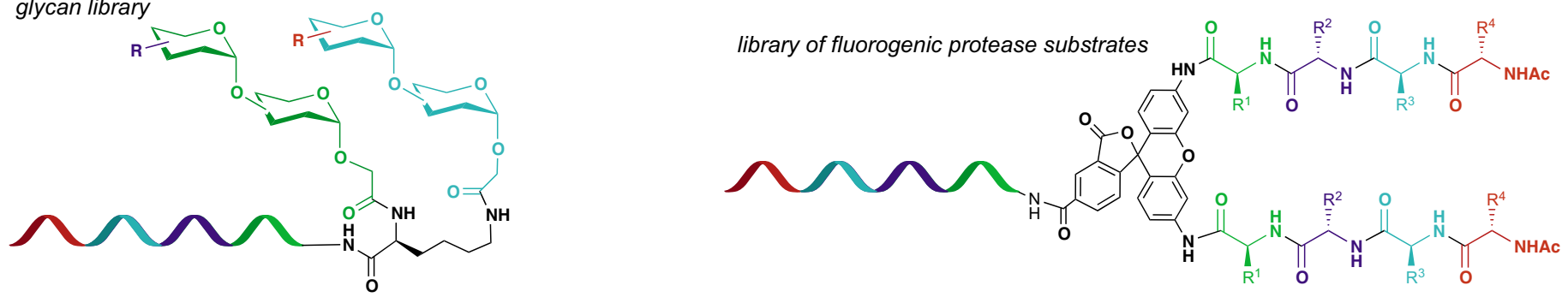

Fig. 2. A. Schematic representation of PNA-encoded synthesis (PES). B. Selected examples of library reported by our lab using PES.

lated distances in the optimal templated assembly were consistent with the available structural information. While neither of the fragments making up the assembly had measurable affinity for $2 \mathrm{G} 12$, the optimal geometry had $4.2 \mu \mathrm{M}$ affinity thus demonstrating a clear synergy in the interaction (Fig. 5.1). If the distance between the hybridization was extended to a 30-nucleobase spacing, the affinity dropped 20 fold. While this example illustrated the concept for a protein-carbohydrate interaction, the generality of this concept extends beyond the latter since it is a recurrent feature in cellular recognition and communication, with many signal transduction pathways being regulated by multimeric interactions in homo- or heteromeric interactions. A second example from our group used nucleic acid-templated assemblies to gain insight into the optimal dimerization geometry of macrocyclic peptides targeting the DR5 receptor. ${ }^{[41]}$ This receptor belongs to the super family of TRAIL receptors and mediates an apoptotic signal in response to cytokines. ${ }^{[54]}$ Using a macrocyclic peptide known to bind to the monomeric DR5 receptor, ${ }^{[55]}$ different dimerization geometries were investigated (Fig. 5.2). The optimal assembly achieved an approximately 10-fold longer dissociation halflife than the ligand itself $\left(\mathrm{t}_{1 / 2}\right.$ of 4 min vs $22 \mathrm{sec}$ respectively). ${ }^{[41]}$ These technologies were subsequently applied on a broader scale to small molecules and glycan libraries (Fig. 5.3 and 5.4, see discussion below on selection).

Nucleic acid-programmed pairing is also useful for identifying the optimal geometry in pairing protein fragments (Fig. 5.5). ${ }^{[56]}$ Based on the recent clinical success of bi-specific antibodies, ${ }^{[57]}$ a strategy to rapidly access and evaluate bi-specific or higher order oligomers should facilitate the discovery of the optimal pairing, geometry and valency. In collaboration with the groups of Schultz and Smider, a series of antibody fragments (FAB: fragment antigen binding) incorporating an unnatural amino acid (UAA) with orthogonal chemical reactivity (ketone) ${ }^{[58]}$ were coupled to PNA tags bearing a hydroxyl amine. These constructs were then self-assembled into well-defined multimeric complexes. A 12mer PNA tag afforded sufficient duplex stability for the assembly to be purified by SDS-PAGE gel, and withstand long incubation times in serum without degradation. An $\alpha$ Her2 PNA-linked homodimer was identified that exhibits comparable in vitro activity to the FDA approved drug, trastuzumab. The $\alpha \mathrm{Her} 2$ tetramer showed an $\mathrm{EC}_{50}$ of $4.6 \mathrm{nM}$ in a cellular assay, which is 6-fold lower than trastuzumab illustrating the potential of the technology. In addition, the generality of this approach enabled us 
to synthesize two heterodimers with $\alpha \mathrm{CD} 3$ Fab $(\alpha$ Her $2-\alpha$ CD3 and $\alpha$ CD $20-\alpha C D 3)$ that were potent in targeting T-cells to tumor cells in vitro. Since the multimeric constructs can be rapidly generated by mixing the relevant Fab-PNA subunits, libraries of 'binders' and 'effectors' such as T-cell recruitment, complement fixation, toxin activity components can be easily 'mixed and matched' for in vitro functional testing. Furthermore, this technology can also be used to attach PNA-drugs or contrast agents to create site-specific antibody drug conjugates (ADCs) and imaging agents.

The studies described above were performed in solution, but similar strategies on a microarray format can spatially resolve each assembly (Fig. 5.6).[42] We have used this approach to assemble a diverse array of glycans from simpler libraries (two sets of 25 glycans were paired in 625 permutations). Microarrays containing immobilized carbohydrates ('glycan arrays') have been particularly useful to interrogate the binding selectivity of carbohydrate binding proteins and the detection of pathogens or antibodies as markers for given pathologies. ${ }^{59-62]}$ However, acquiring a large collection of glycans suitably derivatized for chemoselective immobilization in a microarray format is a significant challenge that has restrained most studies to focused glycan libraries. Thus, the ability to access a comparable glycan diversity space through self-assembly would facilitate access to glycan arrays. In order to demonstrate that the combinatorially assembled fragments interact synergistically to a target and essentially emulate a more complex glycan, the array was probed with two well-characterized lectins. The binding profile indeed showed the strongest interaction for discrete combinations of two fragments with structures consistent with their known selectivity.

\section{Screening PNA-encoded Libraries}

As previously discussed, the simplicity of split and mix synthesis makes PNAencoded libraries readily available. While the libraries are obtained as a mixture, they can be sorted into a spatially addressable format by hybridization to a DNA microarray. The recent commercialization of custom DNA microarrays with up to $10^{6}$ sequences (Agilent genomics) further facilitates implementation of this technology. The hybridized libraries can be assayed for binding affinity with tagged proteins in order to identify the best binder (Fig. 6A). For example, our group discovered a novel streptavidin binder using a microarraybased screen. ${ }^{[63]}$ Alternatively, the fittest binder in a library can be isolated prior

Templating the assembly of nucleic-acid tagged libraries with controlled pairing, geometry, and valency

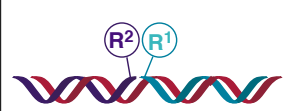

(B) $\left(\mathrm{R}^{1}\right.$
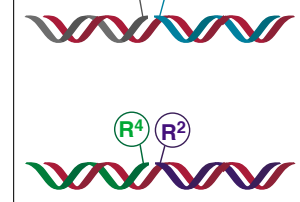

(R) $H \overparen{R^{x}}$
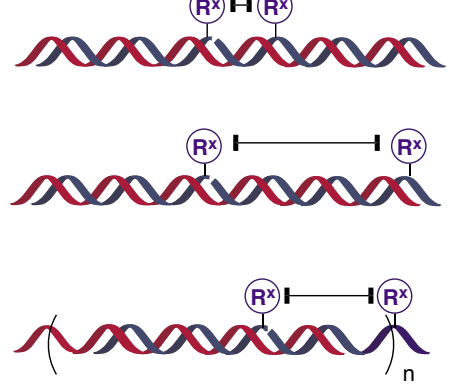

Fig. 3. Templated ligand display. The nucleic acid template allows combinatorial pairing of ligands with different inter-

ligand distances and valencies. Examples shown illustrate each of these aspects individually, but they can also be combined.

For instance, it is possible to combinatorially pair ligands while varying distance and valency.

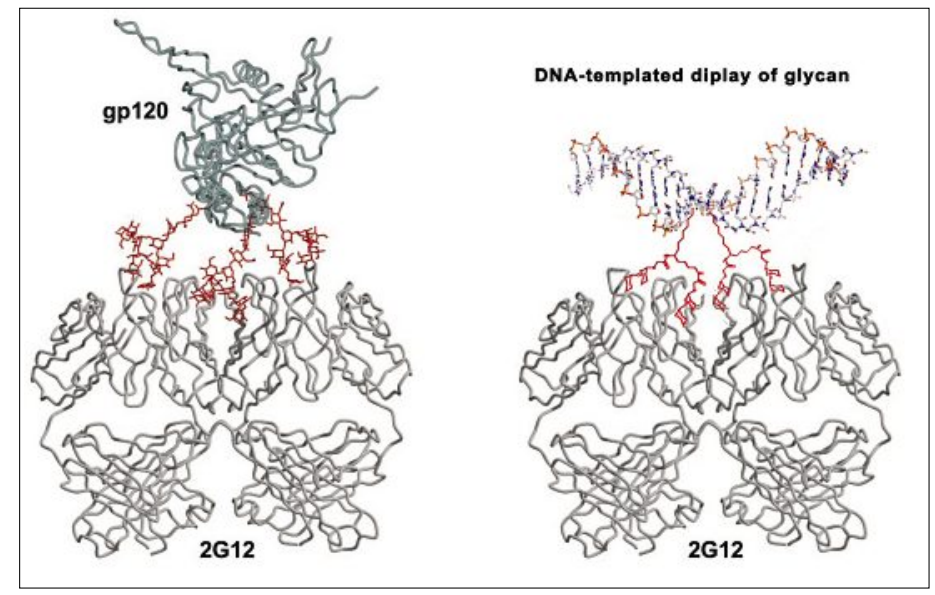

Fig. 4. Model of antibody 2G12 (left) binding HIV's oligosaccharide epitope (left, image adapted from D. A. Clarese, et al., Science, 2003, 300, 2065) and schematic representation of templated assembly of a mannose disaccharide emulating HIV's epitope (right).

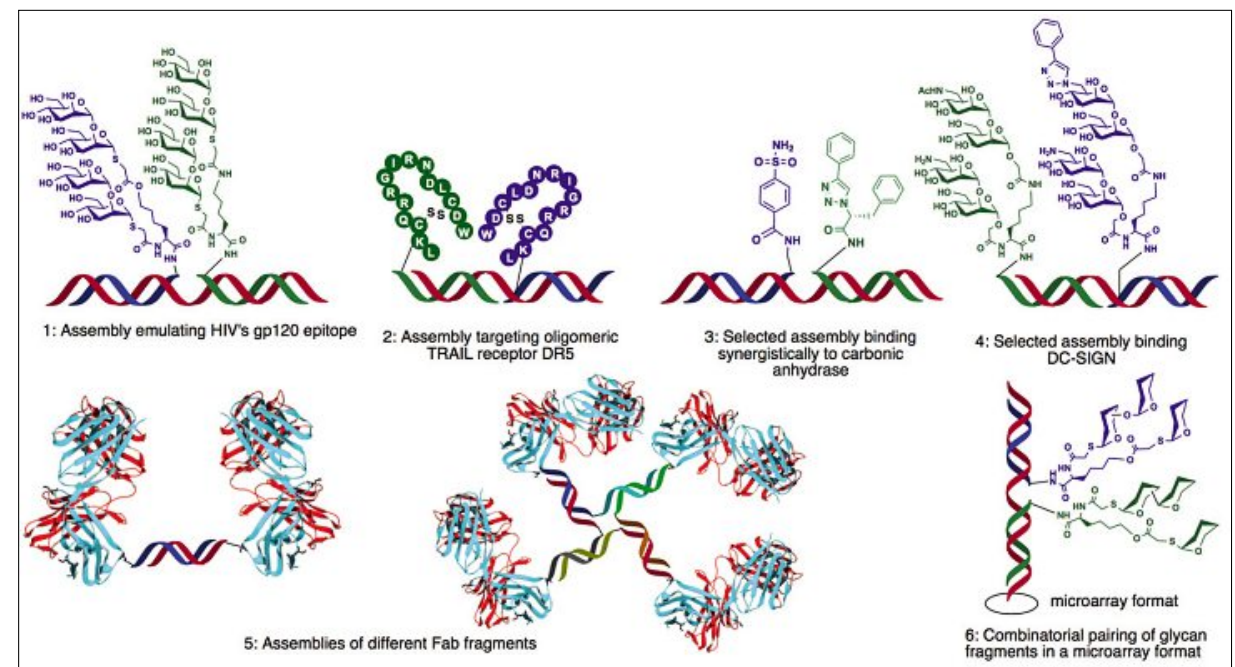

Fig. 5. Selected examples of templated display of ligands reported by our group.

to hybridization via an affinity selection. A simple strategy that was first pursued was to exploit the molecular weight difference between a PNA-conjugate bound to a protein and the free conjugate (Fig. 6B). ${ }^{[26,64]}$ Based on the fact that the PNAencoded small molecule conjugates have a molecular weigh raging from 4-6 KDa, a $30 \mathrm{KDa}$ spin filter was successfully used to remove unbound conjugates from protease targets. This approach was particularly applicable to mechanism-based inhibitors that form a covalent bond to the target and facilitate the size exclusion removal of unbound compound using stringent conditions. A notable asset of this approach is that no labeling of the protein needs to be performed. In fact this strategy can even be carried out with crude proteomic extract as was demonstrated with the identification of proteases from allergenic dust mite. ${ }^{[26]}$ An alternative approach to isolate protein-bound compounds is to use a gel purification (SDS-PAGE). [34] The change in molecular weight between the free protein and its adduct with the PNA conjugate affords a shift on the gel which is indicative of a successful screen. However, the 
challenge of isolating the fittest members from a large library increases with library size. Furthermore, removing unbound compounds by size exclusion or gel is challenging if not unreasonable for noncovalent binder. The remarkable efficacy of biochemical selection systems such as phage display ${ }^{[65]}$ and SELEX ${ }^{[66]}$ to identify binders from large peptide and nucleic acid libraries is facilitated by reiterative selection/amplification cycles. Considering that ligands displayed on a DNA template can bind to a target cooperatively and that the template encoding the fittest pair can be amplified by PCR, we ask whether selecting DNA-templated ligands would enable reiterative screening. From a molecular diversity standpoint, the ability to combine different pharmacophore fragments affords a rapid entry into a large diversity space. ${ }^{[67]}$ This concept was first reduced to practice with a screen against a representative target, carbonic anhydrase, by iterative cycles of affinity selection, amplification of DNA template and 'translation' of the template back into selected library members (Fig. 7). In this example, the fragments were derived on one end from bioactive natural products or FDA approved drugs and on the other end with heterocyclic libraries obtained by PES.[32] The combinatorial output of the fragments produced a library of 62500 combinations that were assembled on a template flanked by two primers. Following the affinity selection against immobilized carbonic anhydrase, the selected templates were amplified by PCR using a biotinylated primer thus enabling the templating strand to be captured on a streptavidin resin. The second primer in the PCR reaction was labeled with a fluorophore in order to hybridize the PCR product to a microarray and analyze the selection process. Exposure of templating strand to the library of PNA-encoded fragments captured the selected fragments, the unselected fragments being removed in the wash. Release from the streptavidin resin afforded the assemblies that were selected in the previous round. Thus, the PCR-amplified templates could be converted back into the selected assemblies. It was shown that reiteration of the cycle of selection/amplification provided a convergence towards a fragment set (see Fig. 5.3 for selected fragments) which, upon re-synthesis as a covalent adduct had an affinity of $87 \mathrm{nM}$ for carbonic anhydrase (neither fragment had an affinity below the $\mu \mathrm{M}$ ). The same strategy was used to optimize binders to DC-SIGN (dendritic cell-specific intercellular adhesion molecule-3-grabbing nonintegrin) with a glycan library. ${ }^{[35]}$ DC-SIGN is a tetrameric lectin implicated in interactions with a broad array of pathogens and has been hijacked by some pathogens such as HIV to shuttle to lymph nodes and interact

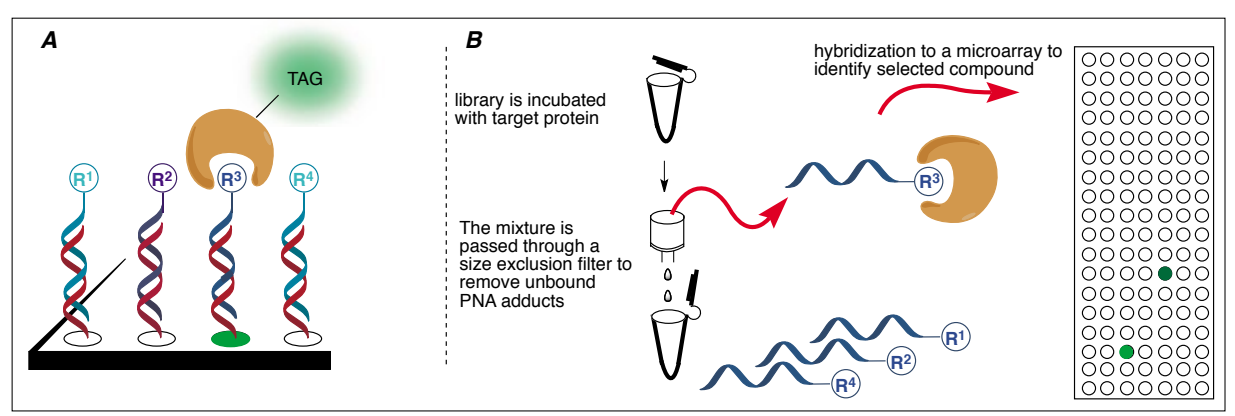

Fig. 6. Screening of PNA-encoded libraries. $A$. The library is self-sorted on a microarray and interrogated with a tagged protein. $B$. The best binder from a library is selected by size exclusion separation and identified following a microarray hybridization.

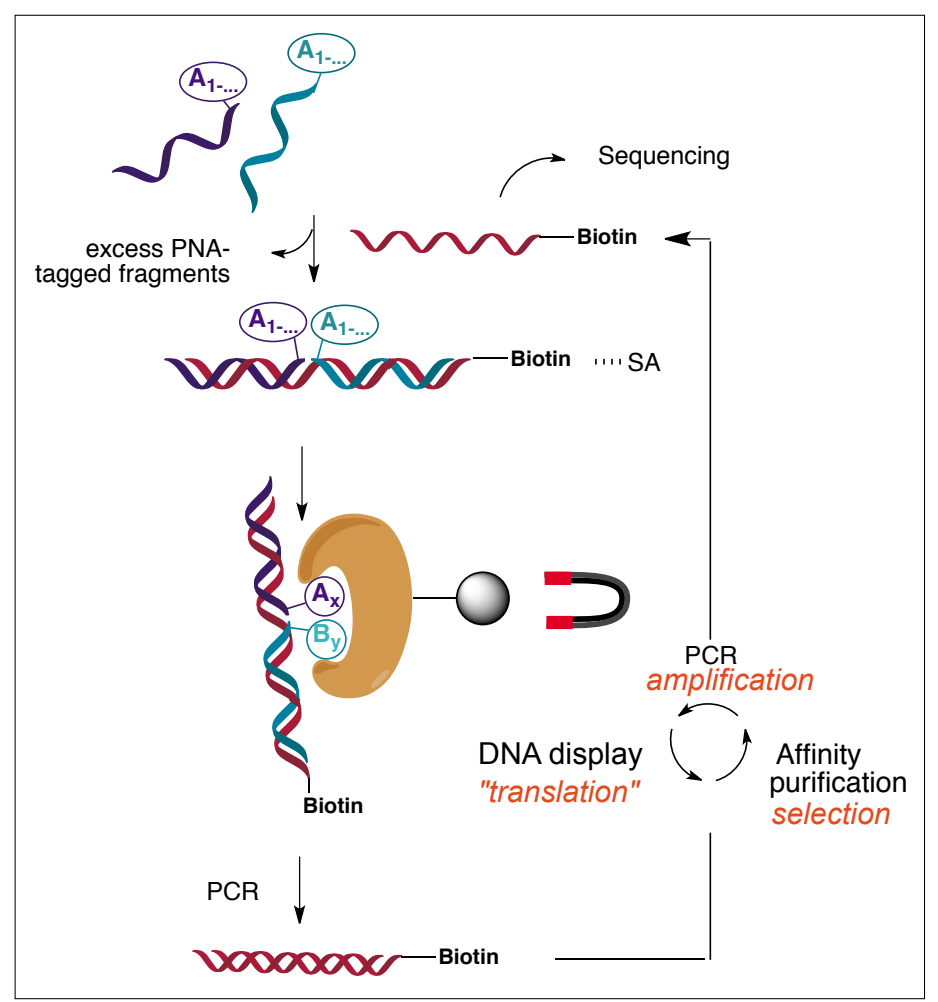

Fig. 7. Screening of DNA-templated libraries by reiterative cycles of affinity selection/amplification.

with $\mathrm{CD}^{+}{ }^{+} \mathrm{T}$ cells. In this example, screening a library of over 37000 members led to the identification of an assembly with 30-fold improved binding over the unmodified mannose assembly (see Fig. 5.4 for selected fragments, neither fragment had measurable affinity individually). Notably, a dendrimer derivatized with the identified ligand was able to outcompete the interaction of HIV's gp120 with dendritic cell at $10 \mu \mathrm{M}$. Taken together, these examples demonstrate that DNA-display extends the scope of reiterative selection/amplification technologies to glycans and small molecules broadly recognized as versatile pharmacophores.

\section{Templated Reaction}

Nucleic acid-templated reactions must have been an important step in prebiotic chemistry and as such, have solicited interest over the years. ${ }^{[68]}$ Templated reactions are accelerated by reagent preorganization and concentrations afforded by hybridiza- tion. ${ }^{[69]}$ Beyond questions related to the origin of life, an impressive array of novel templated reactions have been developed over the past decade that do not aim to mimic the native phosphodiester linkage. Instead, templated reactions are engineered to synthesize or transform a product of interest and could be designed to harness cellular nucleic acids as templates. Cellular nucleic acids can be sensed and imaged with reactions leading to fluorescent signal changes. ${ }^{[70-72]}$ While molecular beacons and fluorescent in situ hybridization (FISH) have successfully sensed cellular nucleic acids in a number of studies, ${ }^{[73,74]}$ templated reactions have potential for greater sensitivity by signal amplification and can diminish false positives because nonspecific interactions do not afford reaction. We became interested in the templated Staudinger reaction in light of its compatibility with cellular chemistry and the robustness of azides in biological settings (Fig. 8). ${ }^{75]}$ Using an azide to mask the function of a molecule would allow a templated Staudinger reaction to reveal this function 


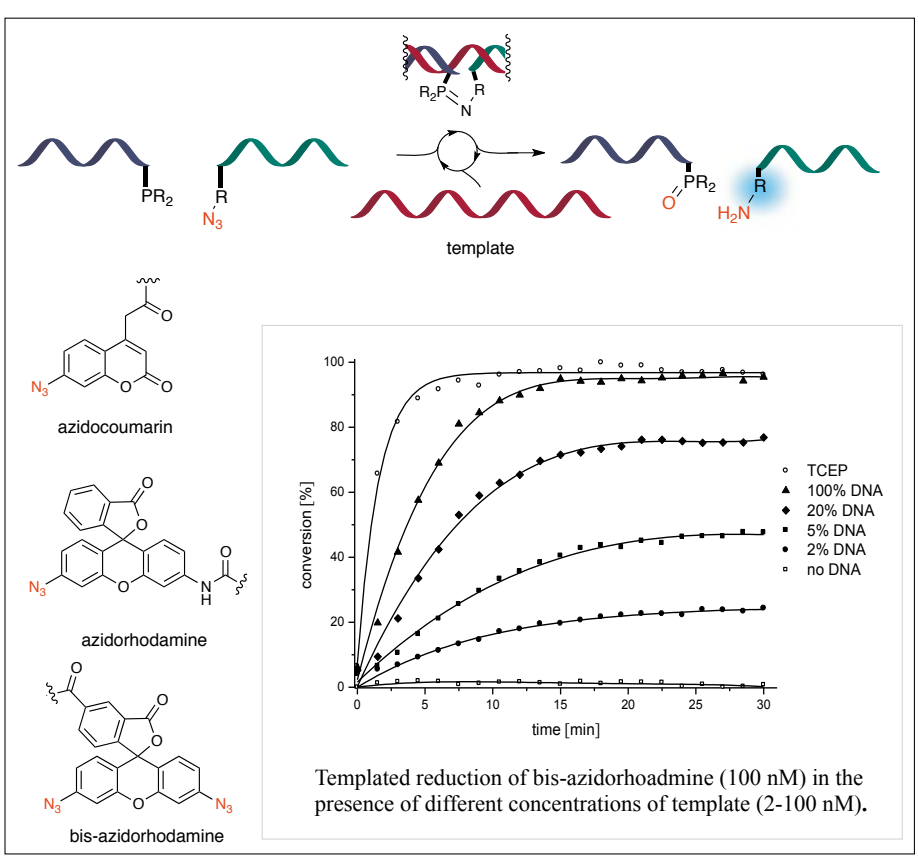

Fig. 8. Nucleic acidtemplated Staudinger reduction (top), structure of different azide-quenched fluorophores reported by our group (left) and kinetics of templated reaction (right).

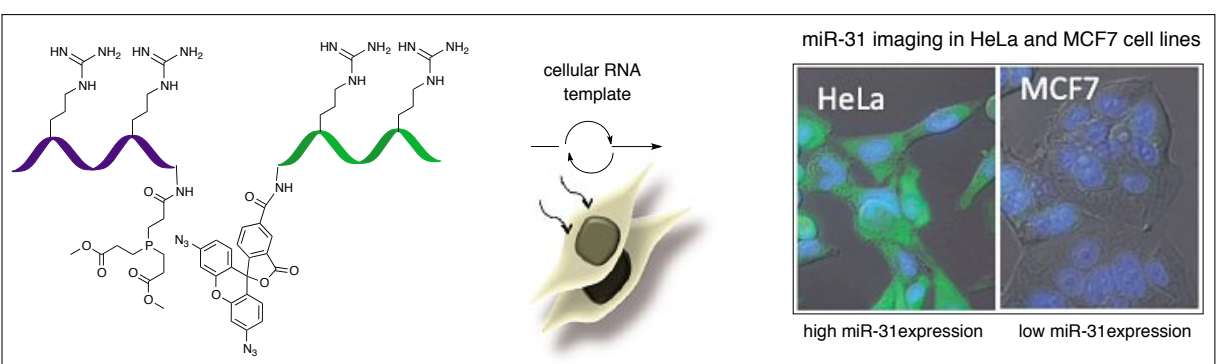

turn-on ratio of azido-rhodamine) was used to image and quantify miRNA across different cell lines using both fluorescence microscopy and flow cytometry (Fig. 9). [78]

Alternatively to azide-quenched profluorophore, a linker that would be cleaved upon azide reduction would offer the possibility to unmask the function of a broader array of molecules (Fig. 10). ${ }^{[84]}$ To this end, we used 4-azidobenzyl carbonate or carbamate linkers, which undergo a 1,6-elimination to release an alcohol, phenol, amine, or aniline, ${ }^{[84]}$ and can be used to mask the function of bioactive small molecules including estradiol (a transcription-factor agonist), doxorubicin (a cytotoxic drug) or the fluorescence of fluorophores such as rhodamine. Attesting to the performance of the reaction, near-quantitative templated uncaging of estradiol was observed after $30 \mathrm{~min}$ of incubation using $50 \%$ template loading (100 nM template).

Despite the impressive achievements associated with the Staudinger reaction, a limitation of this reaction is the propensity of phosphine to oxidize, particularly at the high dilutions of a templated reaction. In practice, this has been circumvented by the use of an excess of phosphine probes. The recent discovery by Liu and coworkers ${ }^{[85]}$ that azides can be photo-catalytically reduced by ruthenium tris-bipyridine led us
Fig. 9. Imaging of cellular nucleic acids using a templated Staudinger reduction with cell permeable GPNA.

without a ligation thus enabling the nucleic acid template to turn over. To this end, we pursued two strategies: i) the development of azide-quenched profluorophores and ii) azide reduction-triggered cleavage of a linker following azide reduction. The use of an azide to mask an electron-donating heteroatom on a fluorophore proved to be a general strategy for generating profluorophores (Fig. 8). We first applied this strategy to coumarin (azidocoumarin ${ }^{[76]}$ ) and then rhodamine (azidorhodamine, ${ }^{[77]}$ bisazidorhodamine ${ }^{[78]}$ ). In parallel, this strategy has been used by other research groups and applied to azidomethyl-fluorescein, ${ }^{[79]}$ azidorhodamine, ${ }^{[80]}$ bis-azidomethyl-fluorescein, ${ }^{[81]}$ and bis-azidonaphtho-rhodamine. ${ }^{[82]}$ The templated unquenching of the profluorophore through azide reduction generally proceeds quickly. Using a first order approximation, a rate constant $(k)$ of $2.76 \times 10^{-3} \mathrm{~s}^{-1}$ was calculated for the Staudinger unquenching of bis-azidorhodamine (Fig 8). ${ }^{[78]}$ To perform the reaction in live cells, GPNA ${ }^{[17]}$ endowed with cellular permeability were used. This enabled the detection of mRNA in live cells using the azidorhodamine fluorophore. ${ }^{[77]} \mathrm{A}$ similar strategy using a bis-azidorhodamine bestowed with higher fluorescence performance (a 120 turn-on ratio vs. the 32-fold
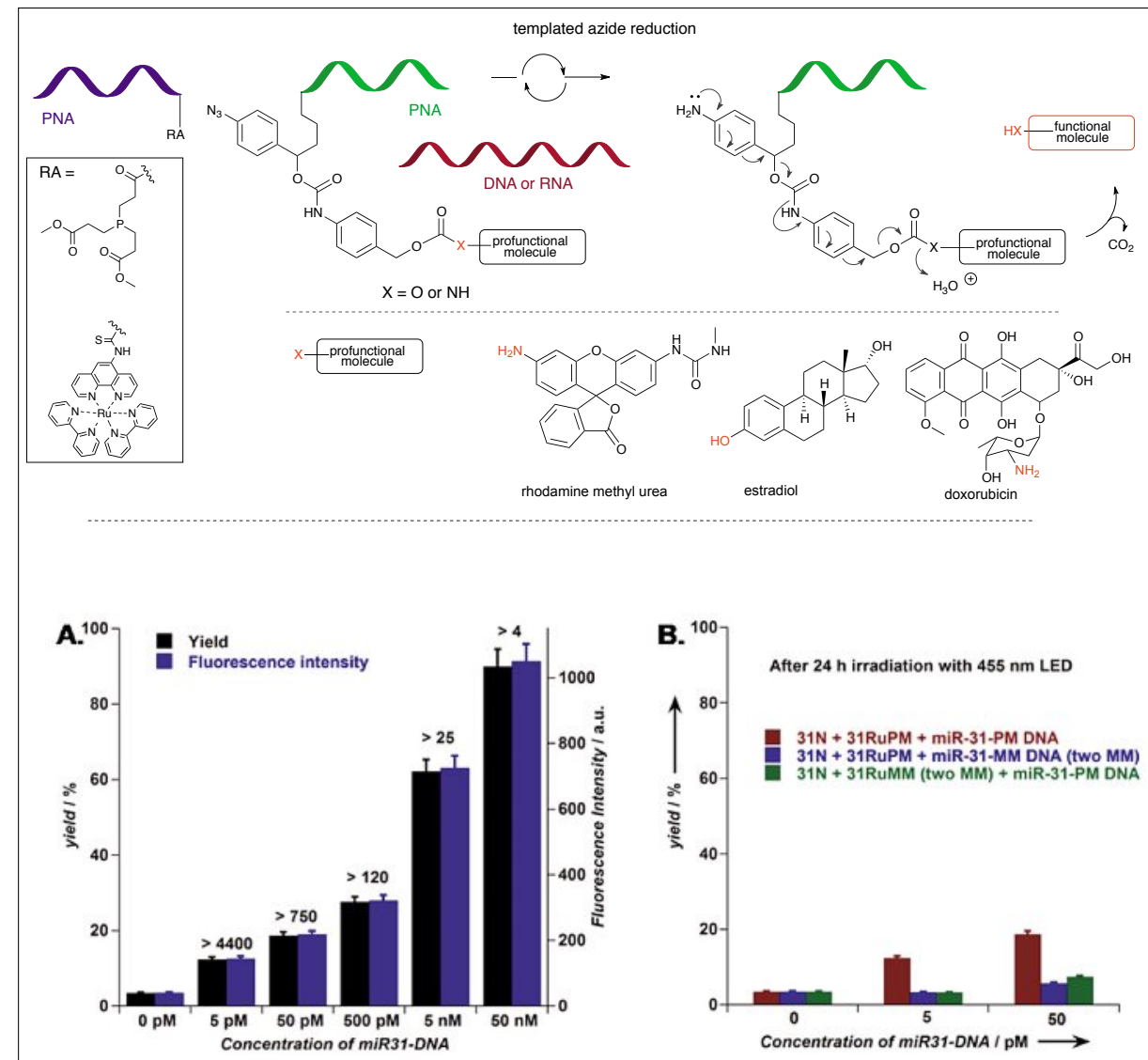

Fig. 10. Nucleic-acid templated immolative linker cleavage. Top: Structure of immolative linker and pro-functional molecules. Bottom: $A$. Signal intensity and turnover (figure above each bar) of the reaction in response to increasing level of template $(0.002$ to $20 \%)$; $B$. Sequence specificity of the reaction relatively to mismatches in the template (blue) and probes (green) at low template loading (0.002 and $0.02 \%)$. 


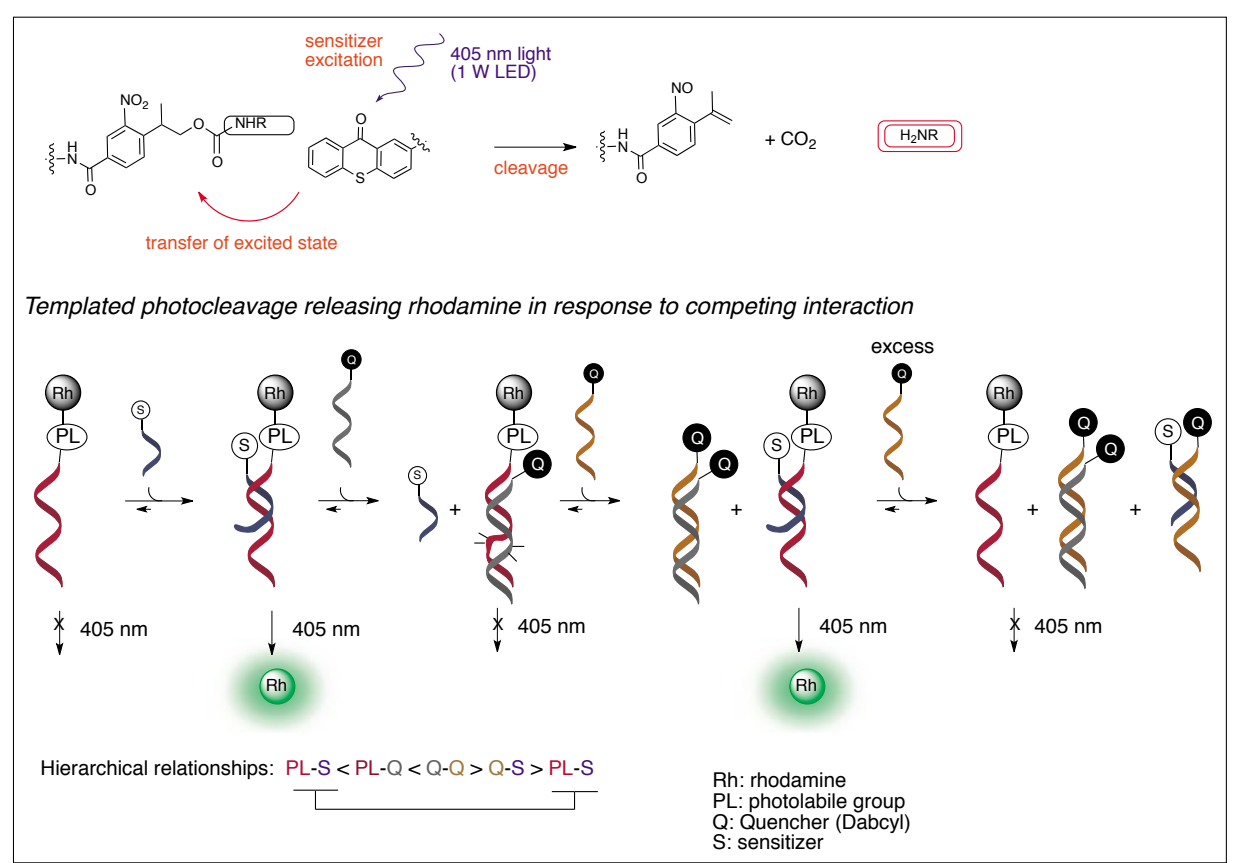

Fig. 11. Top: Structure of photolabile and sensitizer groups used in nucleic acid-templated photocleavage reactions. Bottom: Templated photocleavage in response to competing nucleic acid interactions.

to investigate the use of a ruthenium conjugate instead of the corresponding phosphine. ${ }^{[86]}$ In comparison to the templated Staudinger reaction, this photocatalyzed version proceeded with just $2 \%$ of the $\mathrm{Ru}$ probe and template, leading to the cleavage of the azide-based linker at a comparable rate to that of the Staudinger reaction. This reaction has two advantages over the Staudinger reduction: i) the Ru-conjugate probe can be used in catalytic amount;ii) the reaction is temporally controlled (the reaction is triggered using a $1 \mathrm{~W}$ LED emitting at $455 \mathrm{~nm}$ ) and allows for both probes to be handled at high concentrations without any background reaction. However, while catalytic in ruthenium, the reaction requires a stoichiometric reducing agent (ascorbic acid was used for the in vitro reaction). Nonetheless, the fact that NADPH could be used as the stoichiometric reagent suggested that the cellular redox buffer could be harnessed to perform this reaction in cellulo. ${ }^{\left[{ }^{85]}\right.}$ Gratifyingly, the reaction could indeed be used for sensing cellular nucleic acid and useful for miRNA detection after 30 min irradiation using a $1 \mathrm{~W}$ LED lamp $(455 \mathrm{~nm})$. Furthermore, the reaction was found to proceed with very high level of turnover $(>4000)$ providing reliable detection down to $5 \mathrm{pM}$ of template (Fig 10). ${ }^{[87]}$ For this study, $\gamma$-serine-modified PNA probes were used which are not cell permeable but can be introduced via reversible permeation with streptolysin-O (SLO) or transfection technique. This strategy offers the opportunity to introduce the probes before interrogating the presence of the cellular RNA. For instance, miR-21 in BT474 cells and miR-31 in HeLa cells were selectively detected $24 \mathrm{~h}$ post transfection.
Preliminary experiments in zebra fish have shown that the probes are not toxic, raising hope that this technology could be viable to image nucleic acids at an organism level.

In parallel to the azide-based linker, we explored alternative strategies to uncage molecules with temporal control. Photolabile groups have frequently been used in biology to mask the function of bioactive molecules. Recent reports that the triplet sensitizer thioxanthenone significantly increases the rate of deprotection of the photolabile 2-(2-nitrophenyl) propyloxycarbonyl (NPPOC) protecting group by intramolecular energy transfer ${ }^{[88]}$ inspired us to evaluate whether such energy transfer could not be harnessed in templated reaction (Fig. 11, top). Using a PNA derivatized with a photolabile group that does not cleave with light of wavelength $>300 \mathrm{~nm}$ and a complementary strand with the sensitizer that is excited at 405 $\mathrm{nm}$, we demonstrated that the templated reaction could be used to unmask a fluorophore (rhodamine: $\lambda_{\mathrm{ex}}=490 \mathrm{~nm}, \lambda_{\mathrm{em}}=$ $530 \mathrm{~nm}) .{ }^{[89]}$ Beyond nucleic acid sensing, the combination of strand displacement and templated reactions offers a unique platform for designing dynamic systems that respond in unique ways. Stranddisplacement strategies have been used extensively to engineer logic-gate operations. ${ }^{[90]}$ The templated sensitization of the photolabile group was used to investigate the behavior of systems with up to four components competing for mutual interactions (Fig. 11, bottom). By adjusting the hierarchy of stability among the interactions through the number of base pairs, a system that responds first positively and then negatively to increasing amounts of input was obtained. The unique behavior of this system made it amenable to four different logic operations: AND, NOT, XNOR, and NOR.

The reactions discussed above are enabled by a high effective concentration achieved upon hybridization. Aside from nucleic acid-templated reaction, we asked whether such reactions could not be used to sense protein interactions. Fluorescent probes designed to interrogate protein localization and function are a cornerstone of live cell imaging and a powerful tool for biological investigations. ${ }^{[91]}$ Interrogation of protein homo- or heterodimerization has generally been achieved through the use of two interacting fluorophores leading to a FRET (Förster resonance energy transfer), but should also lend them to a chemical reaction promoted by the high effective concentration achieved upon ligands binding (Fig. 12A). Using a pair of ligands derivatized respectively with the azide-based immolative linker and the $\mathrm{Ru}$ (II) conjugates, the uncaging of rhodamine was achieved using different oligomeric protein templates. ${ }^{\text {[92] }}$ At low concentration, the bi-molecular reaction is slow, however, upon ligand binding, the reactive partners are brought into close proximity thereby increasing their effective concentration and accelerating the reaction. The generality of the approach was validated with three sets of ligands with varying affinity to their target (biotin, desthiobiotin and raloxifene). In all cases the reaction rates of the templated reaction was found to be significantly faster than the background reaction (at least 30-fold faster) providing a clear fluorescent signal in response to the protein oligomer within 30 min at a protein loading between 0.1 and $1 \mu \mathrm{M}$ (see Fig. 12B for response to estrogen receptor). We demonstrated that, as in the case of nucleic acid-templated reaction, substrate turnover did take place affording signal amplification. Interestingly, different reaction rates were observed with increasing length of the linker connecting the ligand to the immolative linker or $\mathrm{Ru}$ conjugate. A linker that was too short completely inhibited the reaction, consistent with the premise that the reagents must be able to reach one another following protein binding. If the linkers were too long, the reaction still took place but at lower speed than the optimal length suggesting that the level of preorganization was not as favorable. The templated reaction was found to also proceed in cellulo and could be used to identify acetyl coenzyme A carboxylase (ACC) in Pseudomonas aeruginosa and human cells using the biotin probes. Similarly, the estrogen receptor was detected in MCF7 cells using the estrogen agonist raloxifene (Fig. 12C). While this study focused on homodimeric or oligo- 
meric targets, the approach should lend itself to heterodimeric or oligomeric interactions as well. Furthermore, this linker is broadly applicable to uncage bioactive small molecules and pharmaceutical compounds, which would be released in a target specific manner.

\section{Summary and Outlook}

It is safe to predict that nucleic acidbased supramolecular assemblies with emerging biological function will have a growing range of applications, whether by controlling dimerization, geometry, con-

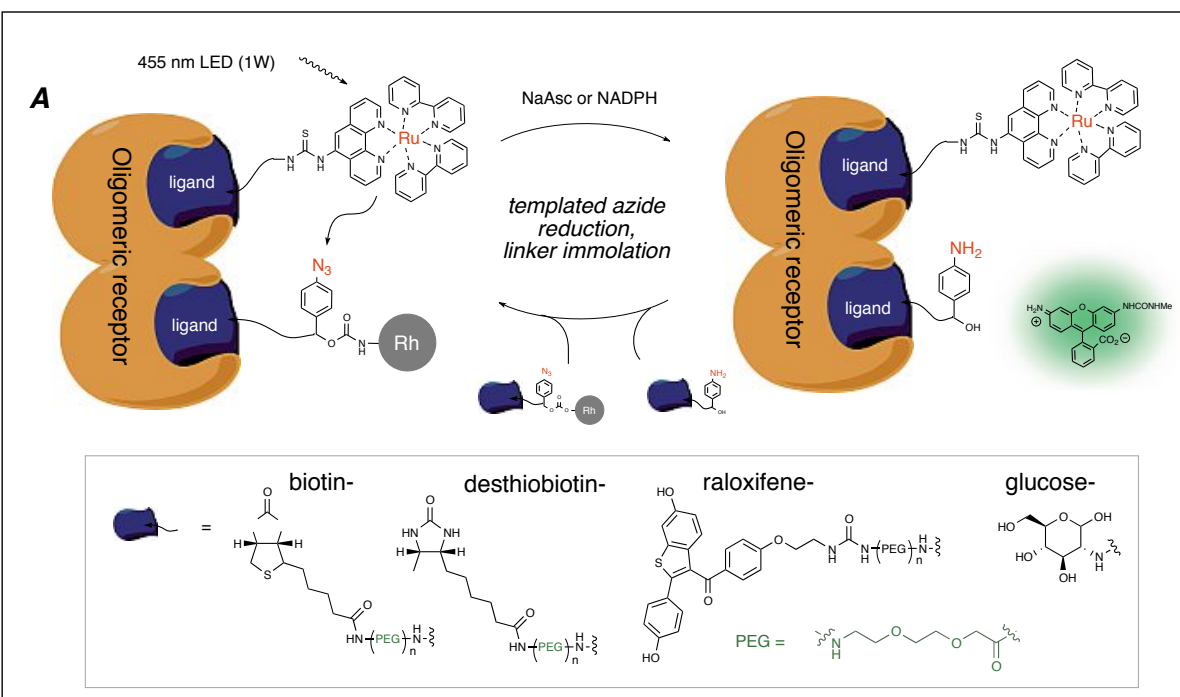

$\boldsymbol{B}$

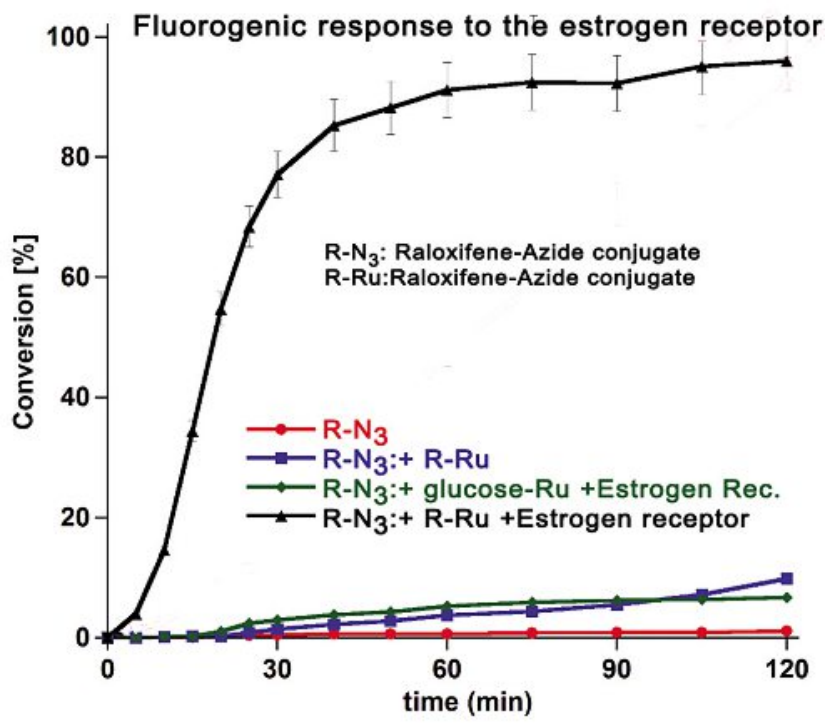

C

\section{Fluorogenic response in MCF7 cells to raloxifene probes}
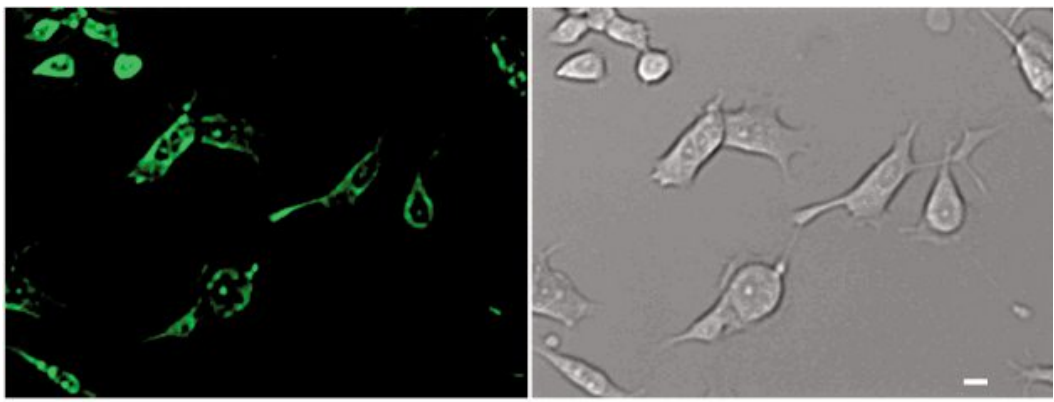

Fig. 12. A. Schematic representation of protein-templated reaction; structure of reactants and ligands. $B$. Fluorogenic response of raloxifene probes in response to estrogen receptor (the receptor is a dimer). C. Cellular imaging of estrogen receptor using templated reaction with raloxifene probes.

formation, or the oligomer order of ligands. While the template architectures that have been used thus far remain simple compared to the achievement in material science, the number of successful examples that have been reported over the past five years should prompt researchers to explore new levels of sophistication. The recent demonstration that PNA-based assemblies are effective in vivo paves the way for their use in medical applications. ${ }^{[93]}$ The use of DNA to display small molecules, peptides, glycans, and biomolecules will benefit from continued improvements in DNA sequencing and analysis technologies (forecasted to surpass Moore's progression of superconductors). This technology offers the possibility of exploring a large molecular diversity space with unprecedented speed. Significant progress has also been made in both the scope of chemical transformations and the functional output of nucleic acid-templated reactions. The fact that several reactions have now been performed in intact cells and have yielded an output that is conditional on the presence of a given nucleic acid holds tremendous potential not only for nucleic acid imaging but also for the development of smart probes that can respond to cellular cue. Both DNA and PNA tagging are useful for small molecule encoding and for templated reactions. From a self-assembly perspective, PNA is effectively a functional analog of DNA. DNA benefits from a more industrialized chemistry and the wealth of its biochemistry (PCR, ligation, sequencing, etc.). However, PNA is more robust, which can facilitate co-synthesis and be an asset in in vivo experiments. The fact that the oligomer is not charged may also prove important in some settings to minimize perturbation of the tag with the biomolecular interaction. The fact that PNA cannot be amplified and sequenced is a notable limitation; the use of DNA to template the assembly of PNA-tagged entities offers a work around this limitation. An important motivation for our work in this area stems from the recognition that much of the complexity of living systems is a product of highly organized self-assembling modules yielding a combinatorial output. Nucleic acid-based assemblies provide a simple means to recapitulate the benefits of combinatorial and spatial organization. Furthermore, its dynamic nature endows it with the ability to respond to environmental cues.

Received: April 17, 2013

[1] Q. Xu, M. R. Schlabach, G. J. Hannon, S. J. Elledge, Proc. Natl. Acad. Sci. USA 2009, 106, 2289.

[2] S. E. Pierce, E. L. Fung, D. F. Jaramillo, A. M. Chu, R. W. Davis, C. Nislow, G. Giaever, Nat. Methods 2006, 3, 601. 
[3] D. D. Shoemaker, D. A. Lashkari, D. Morris, M. Mittmann, R. W. Davis, Nat. Genetics 1996, 14, 450.

[4] E. A. Winzeler, D. D. Shoemaker, A. Astromoff, H. Liang, K. Anderson, B. Andre, R. Bangham, R. Benito, J. D. Boeke, H. Bussey, A. M. Chu, C. Connelly, K. Davis, F. Dietrich, S. W. Dow, M. El Bakkoury, F. Foury, S. H. Friend, E. Gentalen, G. Giaever, J. H. Hegemann, T. Jones, M. Laub, H. Liao, N. Liebundguth, D. J. Lockhart, A. Lucau-Danila, M. Lussier, N. M'Rabet, P. Menard, M. Mittmann, C. Pai, C. Rebischung, J. L. Revuelta, L. Riles, C. J. Roberts, P. Ross-MacDonald, B. Scherens, M. Snyder, S. Sookhai-Mahadeo, R. K. Storms, S. Veronneau, M. Voet, G. Volckaert, T. R. Ward, R. Wysocki, G. S. Yen, K. X. Yu, K. Zimmermann, P. Philippsen, M. Johnston, R. W. Davis, Science 1999, 285, 901.

[5] S. Brenner, R. A. Lerner, Proc. Natl. Acad. Sci. USA 1992, 89, 5381.

[6] A. Furka, F. Sebestyen, M. Asgedom, G. Dibo, Int. J. Pept. Protein Res. 1991, 37, 487.

[7] J. D. Hoheisel, Nat. Rev. Genet. 2006, 7, 200.

[8] J. Shendure, H. L. Ji, Nat. Biotechnol. 2008, 26, 1135.

[9] J. H. Chen, N. C. Seeman, Nature 1991, 350, 631.

[10] N. C. Seeman, Nature 2003, 421, 427

[11] W. M. Shih, J. D. Quispe, G. F. Joyce, Nature 2004, 427, 618.

[12] P. W. K. Rothemund, Nature 2006, 440, 297.

[13] E. S. Andersen, M. Dong, M. M. Nielsen, K. Jahn, R. Subramani, W. Mamdouh, M. M. Golas, B. Sander, H. Stark, C. L. P. Oliveira, J. S. Pedersen, V. Birkedal, F. Besenbacher, K. V. Gothelf, J. Kjems, Nature 2009, 459, 73.

[14] M. Egholm, O. Buchardt, L. Christensen, C. Behrens, S. M. Freier, D. A. Driver, R. H. Berg, S. K. Kim, B. Norden, P. E. Nielsen, Nature 1993, 365, 566.

[15] Z. L. Pianowski, N. Winssinger, Chem. Soc. Rev. 2008, 37, 1330.

[16] T. Sugiyama, A. Kittaka, Molecules 2013, 18, 287.

[17] A. Dragulescu-Andrasi, S. Rapireddy, G. He, B. Bhattacharya, J. J. Hyldig-Nielsen, G. Zon, D. H. Ly, J. Am. Chem. Soc. 2006, 128, 16104.

[18] A. Dragulescu-Andrasi, S. Rapireddy, B. M. Frezza, C. Gayathri, R. R. Gil, D. H. Ly, J. Am. Chem. Soc. 2006, 128, 10258.

[19] E. A. Englund, D. H. Appella, Angew. Chem. Int. Ed. 2007, 46, 1414.

[20] E. A. Englund, D. H. Appella, Org. Lett. 2005, 7, 3465 .

[21] R. E. Kleiner, C. E. Dumelin, D. R. Liu, Chem. Soc. Rev. 2011, 40, 5707.

[22] L. Mannocci, M. Leimbacher, M. Wichert, J. Scheuermann, D. Neri, Chem. Commun. 2011, 47, 12747.

[23] N. Winssinger, Artif. DNA PNA XNA 2012, 3, 105.

[24] T. Kodadek, Nat. Chem. Biol. 2010, 6, 162.

[25] N. Winssinger, R. Damoiseaux, D. C. Tully, B. H. Geierstanger, K. Burdick, J. L. Harris, Chem. Biol. 2004, 11, 1351.

[26] J. Harris, D. E. Mason, J. Li, K. W. Burdick, B. J. Backes, T. Chen, A. Shipway, G. Van Heeke, L. Gough, A. Ghaemmaghami, F. Shakib, F. Debaene, N. Winssinger, Chem. Biol. 2004, 11, 1361.

[27] F. Debaene, L. Mejias, J. L. Harris, N. Winssinger, Tetrahedron 2004, 60, 8677.

[28] Z. J. Gartner, B. N. Tse, R. Grubina, J. B. Doyon, T. M. Snyder, D. R. Liu, Science 2004, $305,1601$.

[29] D. R. Halpin, P. B. Harbury, PLoS Biol. 2004, 2 , E173.

[30] S. Melkko, J. Scheuermann, C. E. Dumelin, D. Neri, Nat. Biotechnol. 2004, 22, 568.

[31] J. L. Harris, N. Winssinger, Chem. Eur. J. 2005, 11,6792 .
[32] J. P. Daguer, M. Ciobanu, S. Alvarez, S. Barluenga, N. Winssinger, Chem. Sci. 2011, 2, 625.

[33] F. Debaene, J. A. Da Silva, Z. Pianowski, F. J. Duran, N. Winssinger, Tetrahedron 2007, 63, 6577.

[34] H. D. Urbina, F. Debaene, B. Jost, C. BoleFeysot, D. E. Mason, P. Kuzmic, J. L. Harris, N. Winssinger, ChemBioChem 2006, 7, 1790.

[35] M. Ciobanu, K.-T. Huang, J.-P. Daguer, S. Barluenga, O. Chaloin, E. Schaeffer, C. G. Mueller, D. A. Mitchell, N. Winssinger, Chem. Commun. 2011, 47, 9321.

[36] F. Debaene, N. Winssinger, Org. Lett. 2003, 5, 4445.

[37] J. J. Diaz-Mochon, L. Bialy, M. Bradley, Org. Lett. 2004, 6, 1127.

[38] S. Pothukanuri, Z. Pianowski, N. Winssinger, Eur. J. Org. Chem. 2008, 3141.

[39] D. Chouikhi, M. Ciobanu, C. Zambaldo, V. Duplan, S. Barluenga, N. Winssinger, Chem. Eur. J. 2012, 18, 12698.

[40] K. Gorska, K.-T. Huang, O. Chaloin, N. Winssinger, Angew. Chem. Int. Ed. 2009, 48, 7695.

[41] K. Gorska, J. Beyrath, S. Fournel, G. Guichard, N. Winssinger, Chem. Commun. 2010, 46, 7742 .

[42] K.-T. Huang, K. Gorska, S. Alvarez, S. Barluenga, N. Winssinger, ChemBioChem 2011, $12,56$.

[43] F. Abendroth, A. Bujotzek, M. Shan, R. Haag, M. Weber, O. Seitz, Angew. Chem. Int. Ed. 2011, 50, 8592 .

[44] H. Eberhard, F. Diezmann, O. Seitz, Angew. Chem. Int. Ed. 2011, 50, 4146.

[45] C. Scheibe, A. Bujotzek, J. Dernedde, M. Weber, O. Seitz, Chem. Sci. 2011, 2, 770.

[46] E. A. Englund, D. Wang, H. Fujigaki, H. Sakai, C. M. Micklitsch, R. Ghirlando, G. MartinManso, M. L. Pendrak, D. D. Roberts, S. R. Durell, D. H. Appella, Nat. Commun. 2012, 3, 614.

[47] D. Sil, J. B. Lee, D. Luo, D. Holowka, B. Baird, ACS Chem. Biol. 2007, 2, 674.

[48] K. I. Sprinz, D. M. Tagore, A. D. Hamilton, Bioorg. Med. Chem. Lett. 2005, 15, 3908.

[49] B. A. R. Williams, C. W. Diehnelt, P. Belcher, M. Greving, N. W. Woodbury, S. A. Johnston, J. C. Chaput, J. Am. Chem. Soc. 2009, 131, 17233.

[50] R. Liu, B. Jiang, H. Y. Yu, J. C. Chaput, ChemBioChem 2011, 12, 1813 .

[51] K. Matsuura, M. Hibino, Y. Yamada, K. Kobayashi, J. Am. Chem. Soc. 2001, 123, 357.

[52] K. Matsuura, M. Hibino, T. Ikeda, Y. Yamada, K. Kobayashi, Chem. Eur. J. 2004, 10, 352.

[53] D. A. Calarese, C. N. Scanlan, M. B. Zwick, S. Deechongkit, Y. Mimura, R. Kunert, P. Zhu, M. R. Wormald, R. L. Stanfield, K. H. Roux, J. W. Kelly, P. M. Rudd, R. A. Dwek, H. Katinger, D. R. Burton, I. A. Wilson, Science 2003, 300, 2065.

[54] A. Ashkenazi, V. M. Dixit, Science 1998, 281, 1305.

[55] V. Pavet, J. Beyrath, C. Pardin, A. Morizot, M.-C. Lechner, J.-P. Briand, M. Wendland, W. Maison, S. Fournel, O. Micheau, G. Guichard, H. Gronemeyer, Cancer Res. 2010, 70, 1101.

[56] S. A. Kazane, J. Y. Axup, C. H. Kim, M. Ciobanu, E. D. Wold, S. Barluenga, B. A. Hutchins, P. G. Schultz, N. Winssinger, V. V. Smider, J. Am. Chem. Soc. 2013, 135, 340.

[57] R. Bargou, E. Leo, G. Zugmaier, M. Klinger, M. Goebeler, S. Knop, R. Noppeney, A. Viardot, G. Hess, M. Schuler, H. Einsele, C. Brandl, A. Wolf, P. Kirchinger, P. Klappers, M. Schmidt, G. Riethmuller, C. Reinhardt, P. A. Baeuerle, P. Kufer, Science 2008, 321, 974.

[58] L. Wang, Z. W. Zhang, A. Brock, P. G. Schultz, Proc. Natl. Acad. Sci. USA 2003, 100, 56.
[59] J. Stevens, O. Blixt, T. M. Tumpey, J. K. Taubenberger, J. C. Paulson, I. A. Wilson, Science 2006, 312, 404.

[60] M. D. Disney, P. H. Seeberger, Chem. Biol. 2004, 11, 1701

[61] C. Y. Huang, D. A. Thayer, A. Y. Chang, M. D. Best, J. Hoffmann, S. Head, C. H. Wong, Proc. Natl. Acad. Sci. USA 2006, 103, 15.

[62] C. C. Wang, Y. L. Huang, C. T. Ren, C. W. Lin, J. T. Hung, J. C. Yu, A. L. Yu, C. Y. Wu, C. H. Wong, Proc. Natl. Acad. Sci. USA 2008, 105, 11661.

[63] J. P. Daguer, M. Ciobanu, S. Barluenga, N. Winssinger, Org. Biomol. Chem. 2012, 10, 1502 .

[64] N. Winssinger, S. Ficarro, P. G. Schultz, J. L. Harris, Proc. Natl. Acad. Sci. USA 2002, 99, 11139 .

[65] G. P. Smith, Science 1985, 228, 1315.

[66] C. Tuerk, L. Gold, Science 1990, 249, 505

[67] P. J. Hajduk, J. Greer, Nat. Rev. Drug Discov. 2007, 6, 211.

[68] L. E. Orgel, Crit. Rev. Biochem. Mol. Biol. 2004, 39, 99.

[69] X. Li, D. R. Liu, Angew. Chem. Int. Ed. 2004, $43,4848$.

[70] A. P. Silverman, E. T. Kool, Chem. Rev. 2006, 106, 3775.

[71] D. M. Kolpashchikov, Chem. Rev. 2010, 110, 4709 .

[72] A. Shibata, H. Abe, Y. Ito, Molecules 2012, 17, 2446.

[73] H. J. Tanke, R. W. Dirks, T. Raap, Curr. Opin. Biotechnol. 2005, 16, 49.

[74] S. Tyagi, Nat. Methods 2009, 6, 331

[75] E. M. Sletten, C. R. Bertozzi, Angew. Chem. Int. Ed. 2009, 48, 6974.

[76] Z. L. Pianowski, N. Winssinger, Chem. Commun. 2007, 3820

[77] Z. Pianowski, K. Gorska, L. Oswald, C. A. Merten, N. Winssinger, J. Am. Chem. Soc. 2009, $131,6492$.

[78] R. M. Franzini, E. T. Kool, Org. Lett. 2008, 10, 2935.

[79] K. Gorska, I. Keklikoglou, U. Tschulena, N. Winssinger, Chem. Sci. 2011, 2, 1969.

[80] H. Abe, J. Wang, K. Furukawa, K. Oki, M. Uda, S. Tsuneda, Y. Ito, Bioconjug. Chem. 2008, 19, 1219.

[81] K. Furukawa, H. Abe, K. Hibino, Y. Sako, S. Tsuneda. Y. Ito, Bioconjug. Chem. 2009, 20, 1026; K. Furukawa, H. Abe, Y. Tamura, R. Yoshimoto, M. Yoshida, S. Tsuneda, Y. Ito, Angew. Chem. Int. Ed. 2011, 50, 12020.

[82] K. Furukawa, H. Abe, J. Wang, M. Uda, H. Koshino, S. Tsuneda, Y. Ito, Org. Biomol. Chem. 2009, 7, 671 .

[83] R. M. Franzini, E. T. Kool, J. Am. Chem. Soc. 2009, 131, 16021

[84] K. Gorska, A. Manicardi, S. Barluenga, N. Winssinger, Chem. Commun. 2011, 47, 4364.

[85] Y. Chen, A. S. Kamlet, J. B. Steinman, D. R. Liu, Nat. Chem. 2011, 3, 146.

[86] M. Rothlingshofer, K. Gorska, N. Winssinger, Org. Lett. 2012, 14, 482.

[87] K. K. Sadhu, N. Winssinger, Chem. Eur. J. 2013, DOI: $10.1002 /$ chem. 201300060

[88] D. Woll, J. Smirnova, W. Pfleiderer, U. E. Steiner, Angew. Chem. Int. Ed. 2006, 45, 2975.

[89] M. Rothlingshofer, K. Gorska, N. Winssinger, J. Am. Chem. Soc. 2011, 133, 18110.

[90] L. Qian, E. Winfree, Science 2011, 332, 1196.

[91] B. N. G. Giepmans, S. R. Adams, M. H. Ellisman, R. Y. Tsien, Science 2006, 312, 217.

[92] K. K. Sadhu, T. Eierhoff, W. Romer, N. Winssinger, J. Am. Chem. Soc. 2012, 134, 20013.

[93] E. A. Englund, D. Y. Wang, H. Fujigaki, H. Sakai, C. M. Micklitsch, R. Ghirlando, G. Martin-Manso, M. L. Pendrak, D. D. Roberts, S. R. Durell, D. H. Appella, Nat. Commun. 2012, 3, 160 . 